\title{
Proteomic Analysis Reveals Proteins Involved in Seed Imbibition under Salt Stress in Rice
}

\author{
Enshun $\mathrm{Xu}^{1+}$, Mingming Chen ${ }^{2+}$, Hui He ${ }^{1}$, Chengfang Zhan ${ }^{1}$, Yanhao Cheng ${ }^{1}$, \\ Hongsheng Zhang ${ }^{1 *}$ and Zhoufei Wang ${ }^{1 *}$ \\ ${ }^{1}$ The Laboratory of Seed Science and Technology, State Key Laboratory of Crop Genetics and Germplasm Enhancement, \\ Jiangsu Collaborative Innovation Center for Modern Crop Production, Nanjing Agricultural University, Nanjing, China, \\ ${ }^{2}$ Department of Plant Science, College of Biological Sciences, Henan Agricultural University, Zhengzhou, China
}

\section{OPEN ACCESS}

Edited by:

Maoteng Li,

Huazhong University of Science and

Technology, China

Reviewed by:

Magdalena Maria Julkowska, King Abdullah University of Science and Technology, Saudi Arabia

Zhulong Chan,

Huazhong Agricultural University,

China

Kun Wang

Wuhan University, China

*Correspondence:

Hongsheng Zhang

hszhang@njau.edu.cn

Zhoufei Wang

wzf@njau.edu.cn

${ }^{\dagger}$ These authors have contributed equally to this work.

Specialty section:

This article was submitted to Crop Science and Horticulture,

a section of the journal

Frontiers in Plant Science

Received: 19 September 2016 Accepted: 16 December 2016

Published: 05 January 2017

Citation:

Xu E, Chen M, He H, Zhan C, Cheng Y, Zhang $H$ and Wang $Z$ (2017) Proteomic Analysis Reveals Proteins Involved in Seed Imbibition under Salt

Stress in Rice.

Front. Plant Sci. 7:2006 doi: 10.3389/fpls.2016.02006
Enhancement of salinity tolerance during seed germination is very important for direct seeding in rice. In this study, the salt-tolerant japonica landrace Jiucaiqing was used to determine the regulators that are involved in seed imbibition under salt stress. Briefly, the comparative proteomic analysis was conducted between dry $(0 \mathrm{~h})$ and imbibed (24 h) seeds with $150 \mathrm{mM} \mathrm{NaCl}$. Under salt stress, the uptake of water increased rapidly before $24 \mathrm{~h}$ imbibition (Phase I), followed by a plateau of seed imbibition from 24 to $96 \mathrm{~h}$ imbibition (Phase II). We identified 14 proteins involved in seed imbibition, in which the majority of these proteins were involved in energy supply and storage protein. The early imbibition process was mediated by protein catabolism; the most of proteins were down-regulated after $24 \mathrm{~h}$ imbibition. Eleven genes in salt stress treated seeds were expressed early during the seed imbibition in comparison to control seeds. By comparison, 2,3-bisphosphoglycerate-independent phosphoglycerate mutase (BPM), glutelin (GLU2.2 and GLU2.3), glucose-1-phosphate adenylyltransferase large subunit (GAS8), and cupin domain containing protein (CDP3.1 and CDP3.2) were near the regions of quantitative trait loci (QTLS) for seed dormancy, seed reserve utilization, and seed germination in Jiucaiqing. In particular, CDP3.1 was co-located in the region of qIR-3 for imbibition rate, and qGP-3 for germination percentage. The role of CDP3.1 was verified in enhancing seed germination under salt stress using T-DNA mutant. The identified proteins might be applicable for the improvement of seed germination under salt stress in rice.

Keywords: rice, seed germination, seed imbibition, comparative proteomics, salt stress

\section{INTRODUCTION}

Rice (Oryza sativa L.) is a salt-sensitive crop. However, about $30 \%$ of the rice growing area in the world were affected by salinity (Takehisa et al., 2004) due to defective irrigation and fertilization (Lin et al., 2004). Salinity causes water deficit, ion toxicity, and nutrient deficiency, which can result in growth and yield reduction and even plant death (Maggio et al., 2010). The direct seeding method recently has become increasingly important in many Asian countries due to its lower cost and operational simplicity (Fujino et al., 2004; Wang et al., 2011). Therefore, improving seed germination under salt stress is an important goal for rice breeding.

Understanding the mechanisms of seed germination is helpful to develop the elite varieties with high seed vigor. In recent years, several proteomics analyses of seed germination had been applied in rice (Sano et al., 2012; Han et al., 2014a,b; Xu et al., 2016; Zhang et al., 2016). 
For example, it was reported by Sano et al. (2012) that de novo transcription was not required for rice seed germination. They also showed that some of the germination-specific proteins involved in energy production and maintenance of cell structure was synthesized from long-lived mRNAs. In addition, it has been showed that the proteins involved in carbohydrate metabolism and protein synthesis/catabolism were predominantly increased during rice seed germination (Han et al., 2014b). The carbonylated proteins were found to be mainly involved in maintaining the levels of ROS, abscisic acid, and seed reserves during rice seed germination (Zhang et al., 2016). Several important proteins were observed to be associated with rice seed germination involved in metabolism, energy production, protein synthesis, and destination, storage protein, cell growth and division, signal transduction, cell defense, and rescue (Xu et al., 2016). However, the proteomics analyses of seed imbibition under salt stress is scarcely reported in rice.

Based on the uptake of water, seed imbibition can be divided into three phases-a rapid uptake of water (Phase I), followed by a plateau phase of water uptake (Phase II), and a rapid uptake of water with the initiation of growth (Phase III; Wang et al., 2011; Cheng et al., 2017). During seed's imbibition, Phase II represents a critical development stage, in which all the necessary metabolic pathways and physiological processes are reactivated (Yang et al., 2007; He et al., 2011). It is found that germination process is highly disturbed by salt stress. The excessive concentrations of $\mathrm{Na}^{+}$and $\mathrm{Cl}^{-}$ions, reduction in osmotic potential, and ion toxic effects might be responsible for low seed germination under salt stress. Previously, we have identified one salt-tolerant japonica landrace Jiucaiqing from Taihu Lake valley in Jiangsu Province of China (Wang et al., 2011, 2012a,b). By using bi-parental population, we have identified several quantitative trait locus (QTLs) in Jiucaiqing for seed dormancy (Wang et al., 2014), seed reserve utilization (Cheng et al., 2013), seed vigor (Liu et al., 2014), and salt tolerance at seed germination (Wang et al., 2011) and seedling stages (Wang et al., 2012a,b). Recently, we found that the proteins associated with seed imbibition in distilled water could be categorized as carbohydrate and protein biosynthesis and metabolism-related, signaling-related, storage, and stressrelated proteins in Jiucaiqing (Cheng et al., 2017). However, the regulators involved in seed imbibition under salt stress are still not certain.

In this study, two-dimensional gel electrophoresis (2-DE) was used to identify the proteins involved in seed imbibition under salt stress in rice. Fourteen proteins were identified. Among them, six proteins were near the regions of the previous QTLs for seed germination. Furthermore, one of the protein, cupin domain containing protein (CDP3.1), was chosen for verification and found to enhance seed germination under salt stress. These results will increase our understanding on rice seed germination under salt stress.

\section{MATERIALS AND METHODS}

\section{Plant Materials}

The landrace Jiucaiqing (Oryza sativa spp. japonica) was used from the Taihu Lake valley in Jiangsu Province of China (Du et al., 2015; Cheng et al., 2017). Seeds were provided by the Laboratory of Seed Science and Technology in Nanjing Agricultural University (Nanjing, Jiangsu Province, China). All seeds were harvested at their maturity stage and dried at $42^{\circ} \mathrm{C}$ for 7 days ( $\sim 13.5 \%$ moisture content) to break seed dormancy (Wang et al., 2011). The T-DNA insertion line PFG_1B-08438.L of CDP3.1 (rice ssp. japonica cv. Dongjin) was ordered from the RISD database (Jeon et al., 2000; Jeong et al., 2002).

\section{Seed Germination}

Seed germination was conducted as previously described Cheng et al. (2017). Fifty seeds in replicate were imbibed in Petri dishes $(d=9 \mathrm{~cm})$ under water or $150 \mathrm{mM} \mathrm{NaCl}$ conditions at 30 $\pm 1^{\circ} \mathrm{C}$ for 10 days. The solution was replaced every $24 \mathrm{~h}$ to maintain the $\mathrm{NaCl}$ concentration. The weight of imbibed seeds was recorded each $12 \mathrm{~h}$ to calculate the moisture content of seeds. Germination ability was observed every day to calculate germination percentage (GP) and seedling percentage (SP) (Du et al., 2015). Seeds were considered as germination when the radicle protruded $(2 \mathrm{~mm})$ through seed coat. Seedlings were considered to be established when the root length reached seed length and the shoot length reached half of seed length. Germination index (GI) was calculated by the method of (Wang et al., 2010): $G I=\Sigma(G t / t)$, where $G t$ is the number of the germinated seeds on day $t$. Three replicates were conducted.

\section{Protein Extraction and Quantification}

Protein extraction and quantification were conducted as previously described by Cheng et al. (2017). Fifty seeds of each replicate were imbibed under $150 \mathrm{mM} \mathrm{NaCl}$ for $24 \mathrm{~h}$, and then frozen in liquid nitrogen and stored at $-80^{\circ} \mathrm{C}$ until further use along with the dry seeds as control. Total proteins were isolated using the tri-chloro-acetic acid (TCA)/acetone method according to $\mathrm{He}$ and $\mathrm{Li}$ (2008), and protein concentration was determined by the Bradford assay kit (Bio-Rad Laboratory, USA; Guo et al., 2004). Three biological replicates were conducted.

\section{Two-Dimensional Electrophoresis and Protein Identification}

Two-dimensional electrophoresis and protein identification were conducted as previously described by Cheng et al. (2017). Total protein $(100 \mu \mathrm{g})$ was loaded onto GE Healthcare $13 \mathrm{~cm}$ IPG gel strips ( $\mathrm{pH} 3-10)$, which were rehydrated overnight. Isoelectric focusing (IEF) of the IPG strips was conducted by using IPGPhor II (GE Healthcare, USA) at $20^{\circ} \mathrm{C}$ for a total of $67.86 \mathrm{kVh}$. The second dimension was performed by using 15\% SDS-PAGE gels on an Ettan Daltsix (GE Healthcare, USA). The running condition was $15 \mathrm{~mA}$ per gel for the first $30 \mathrm{~min}$, followed by $30 \mathrm{~mA}$ per gel until the dye reached the bottom of gel. Gels were visualized with silver nitrate. The 2-DE gels were scanned with an Image Scanner and analyzed by using Image MasterElite software (GE Healthcare, USA). The intensities of the differentially expressed protein spots on the 2-DE gels obtained in three independent experiments were quantitatively measured to obtain statistical information on variations in the protein levels. The spots with fold changes higher than 2.0 and the significant level at $P<0.01$ by Student's $t$-test were considered 


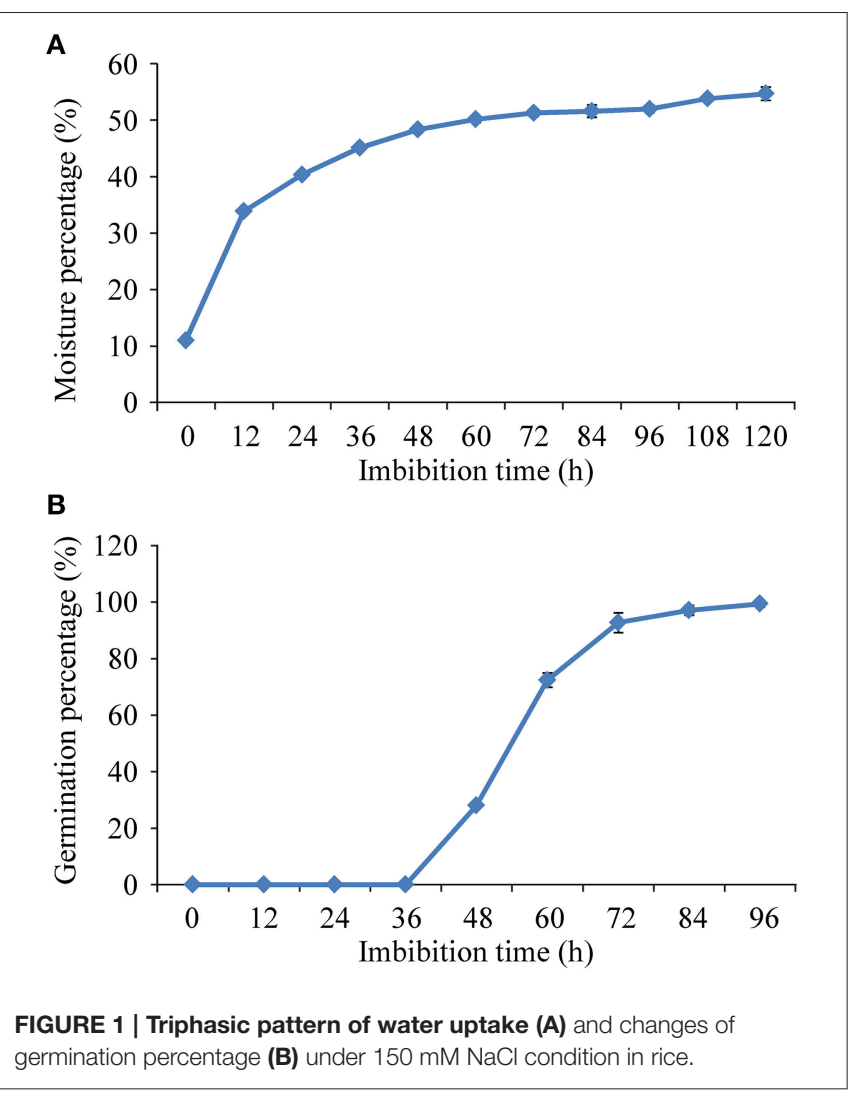

to be differentially expressed proteins between the dry $(0 \mathrm{~h})$ and imbibed $(24 \mathrm{~h})$ seeds.

Those changed spots were manually excised from the gels and subjected to trypsinolysis according to standard techniques (Cheng et al., 2017). A total of $1 \mathrm{~mL}$ of peptides was loaded directly onto the MALDI target for analysis on the Ettan MALDI-TOF Pro system (GE Healthcare, USA) according to Fu et al. (2011). The online search engine Mascot (http://www. matrixscience.com) was used for the identification of proteins based on the NCBI non-redundant database (Fu et al., 2011). The searching parameters were as follows: all entries, parent ion mass tolerance at $50 \mathrm{ppm}, \mathrm{MS} / \mathrm{MS}$ mass tolerance of $0.2 \mathrm{Da}$, cysteine carbamidomethylation as a fixed modification, and methionine oxidation as a variable modification. All the identified proteins should have at least one matched peptide with a probability more than $95 \%$.

\section{Gene Function Annotation and Gene Meta-Analysis}

Gene ontology (GO) based enrichment tests were conducted using Singular Enrichment Analysis (SEA) in AgriGO toolkit (http://bioinfo.cau.edu.cn/agriGO/analysis.php) with a significant level FDR $<0.05$ ( $\mathrm{Du}$ et al., 2010). The gene expression at various developmental stages and tissues of rice was analyzed using the publicly available data from microarray platform-51K Affymetrix chips on Genevestigator (https://www. genevestigator.com/gv/plant.jsp; Cheng et al., 2017).

\section{Quantitative Real-Time PCR}

Fifty seeds each replicate of Jiucaiqing were harvested after 0 , 12,24 , and $48 \mathrm{~h}$ imbibition in distilled water and $150 \mathrm{mM} \mathrm{NaCl}$ solutions, and then were quick-frozen in liquid nitrogen and stored at $-80^{\circ} \mathrm{C}$ for RNA extraction. All seeds were ground to a fine powder with a mortar and pestle on dry ice. Total RNA was extracted from approximately $80 \sim 100 \mathrm{mg}$ powder using the RNeasy plant mini kit (Qiagen, www.qiagen.com) according to the manufacturer's protocol. First-strand cDNAs were synthesized from DNase I (Takara) treated total RNA using Thermo Scientific Revert Aid First Strand cDNA Synthesis kit following the manufacturer's instructions. The mRNA levels of genes were measured by quantitative real-time PCR (qRTPCR) using CFX96 Real-time System (BIO-RAD, USA) with SYBR Green Mix (Vazyme). The rice 18S ribosomal RNA gene was used as an internal control. The PCR conditions were as follows: $95^{\circ} \mathrm{C}$ for $5 \mathrm{~min}$, followed by 40 cycles of $95^{\circ} \mathrm{C}$ for $15 \mathrm{~s}$ and $60^{\circ} \mathrm{C}$ for $30 \mathrm{~s}$. A final ramping stage of $65-95^{\circ} \mathrm{C}$ was performed to confirm the absence of multiple products and primer dimers. All of the primers used for qRT-PCR were designed according to http://quantprime.mpimp-golm.mpg.de/ (Supplementary Table 1). The relative quantification of the transcript levels was measured using the comparative $\mathrm{Ct}$ method (Livak and Schmittgen, 2001). Three biological replicates were conducted.

\section{Mutant Identification}

The T-DNA insertion site and homozygous line of CDP3.1 was confirmed by PCR analysis of genomic DNA using gene-specific primers F1, 5'-AGGAATCCATTTCCGTTCTG- $3^{\prime}, \quad$ R1, $5^{\prime}$-TGGCAACAAAGTGAACAAGC-3', and a T-DNA-specific primer T-DNA-F, $5^{\prime}$-ATGGCAGTGAATTAACATAGC- $3^{\prime}$. The PCR program was (1) $95^{\circ} \mathrm{C}$ for $5 \mathrm{~min},(2) 95^{\circ} \mathrm{C}$ for $45 \mathrm{~s}$, (3) $58^{\circ} \mathrm{C}$ for $45 \mathrm{~s}$, (4) $72^{\circ} \mathrm{C}$ for $1 \mathrm{~min}$, and (5) $72^{\circ} \mathrm{C}$ for $10 \mathrm{~min}$. From steps $2-4$, the cycles were repeated for 35 cycles. PCR products were directly sequenced and BLAST results showed that the T-DNA was inserted in the promotor of CDP3.1 via NCBI BLAST of the rice genome database (https://blast.ncbi.nlm.nih.gov/Blast.cgi). Total RNAs were extracted from WT (wild type) and CDP3.1 mutant ( $c d p 3.1)$ seeds for qRT-PCR analysis as described above. Three biological replicates were conducted.

\section{Evaluation of Seedling Growth and Ion Accumulation in Tissues}

One hundred seeds of wild type and $c d p 3.1$ in replicate were germinated under water and $150 \mathrm{mM} \mathrm{NaCl}$ conditions at 30 $\pm 1^{\circ} \mathrm{C}$ for 11 days. Ten seedlings in replicate were used to measure the fresh and dry weight of seedlings during 7-11 days germination stages. For $\mathrm{Na}^{+}$accumulation analysis, the tissues of seedlings, including grains, shoots, and roots, were harvested and dried after 11 days germination. The seedlings were dried in an oven at $70^{\circ} \mathrm{C}$ for $12 \mathrm{~h}$. Then, at least $0.5 \mathrm{~g}$ of dry tissues was used for acid digestion and ICP-AES analysis according to Møller et al. (2009). The $\mathrm{Na}^{+}$accumulation in un-germinated dry seeds were also detected. The content of $\mathrm{Na}^{+}$was expressed as mg per gram of dry mass. Each measurement was performed on three replicates. 
TABLE 1 | The successful identification of proteins differentially regulated in response to seed imbibition under salt stress in rice.

\begin{tabular}{|c|c|c|c|c|c|c|c|c|}
\hline Spots $^{a}$ & Locus $^{b}$ & Protein $\mathbf{M W}^{\mathrm{c}}$ & Protein $\mathrm{Pl}^{\mathrm{d}}$ & $\begin{array}{l}\text { Protein } \\
\text { Score }\end{array}$ & $\begin{array}{l}\text { Protein } \\
\text { Score C. I. } \%\end{array}$ & Fold change $e^{e}$ & Protein Namef & Gene Abbreviationg \\
\hline 488 & LOC_Os08g25734 & 68861.2 & 6.46 & 359 & 100 & -2.38 & $\begin{array}{l}\text { Glucose-1-phosphate } \\
\text { adenylyltransferase large subunit }\end{array}$ & GAS8 \\
\hline 501 & LOC_Os01g60190 & 60980 & 5.42 & 736 & 100 & -2.36 & $\begin{array}{l}\text { 2,3-bisphosphoglycerate-independent } \\
\text { phosphoglycerate mutase }\end{array}$ & $B P M$ \\
\hline 633 & LOC_Os01g44220 & 57741.6 & 5.48 & 826 & 100 & -5.11 & $\begin{array}{l}\text { Glucose-1-phosphate } \\
\text { adenylyltransferase large subunit }\end{array}$ & GAS1 \\
\hline 706 & LOC_Os08g25734 & 53202.2 & 5.87 & 459 & 100 & -2.95 & $\begin{array}{l}\text { Glucose-1-phosphate } \\
\text { adenylyltransferase large subunit }\end{array}$ & GAS8 \\
\hline 748 & LOC_Os12g13320 & 52501.8 & 6.59 & 299 & 100 & -2.82 & Argininosuccinate synthase & $A R S$ \\
\hline 840 & LOC_Os03g57960 & 52436.3 & 6.78 & 552 & 100 & 2.93 & Cupin domain containing protein & CDP3.1 \\
\hline 870 & LOC_Os06g04200 & 66978.1 & 8.34 & 83 & 99.9 & -2.97 & Granule-bound starch synthase I & GSS \\
\hline 959 & LOC_Os02g07260 & 42195.5 & 5.64 & 195 & 100 & -3.38 & Phosphoglycerate kinase protein & $P K P$ \\
\hline 981 & LOC_Os06g04200 & 66978.1 & 8.34 & 78 & 99.6 & -2.10 & Granule-bound starch synthase I & GSS \\
\hline 1092 & LOC_Os06g04200 & 66978.1 & 8.34 & 125 & 100 & -2.66 & Granule-bound starch synthase I & GSS \\
\hline 1135 & LOC_Os03g57960 & 52436.3 & 6.78 & 447 & 100 & 2.70 & Cupin domain containing protein & CDP3.1 \\
\hline 1159 & LOC_Os05g33570 & 88773.9 & 5.43 & 98 & 100 & -2.00 & Pyruvate phosphate dikinase & $P P D$ \\
\hline 1224 & LOC_Os11g04070 & 34470.1 & 5.38 & 198 & 100 & 3.44 & 60S acidic ribosomal protein & $A R P$ \\
\hline 1426 & LOC_Os02g14600 & 57153.2 & 9.56 & 246 & 100 & -3.08 & Glutelin & GLU2.1 \\
\hline 1462 & LOC_Os03g21790 & 61742.3 & 7.18 & 90 & 100 & 2.68 & Cupin domain containing protein & CDP3.2 \\
\hline 1536 & LOC_Os03g31360 & 50691.4 & 8.74 & 99 & 100 & -2.44 & Glutelin & GLU3 \\
\hline 1652 & LOC_Os02g25640 & 55103.9 & 9.02 & 355 & 100 & -3.48 & Glutelin & GLU2.2 \\
\hline 1981 & LOC_Os02g16820 & 36037.8 & 6.6 & 80 & 99.7 & 9.93 & Glutelin & GLU2.3 \\
\hline
\end{tabular}

${ }^{a}$ Numbers correspond to the 2-DE gels shown in Supplementary Figure 2.

${ }^{b} \mathrm{MSU}$ gene symbol.

${ }^{c}$ Protein molecular weight $(\mathrm{kDa})$.

${ }^{d}$ Protein isoelectric point values.

eprotein fold changes compared to the control (dry seeds). "+" up-regulated; "-" down-regulated after 24 h imbibition.

${ }^{f}$ Protein annotation of the best matching BLAST hit of the rice database in NCBI.

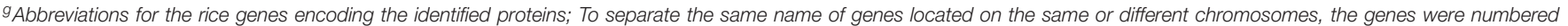
though adding No. of chromosome in the abbreviations.

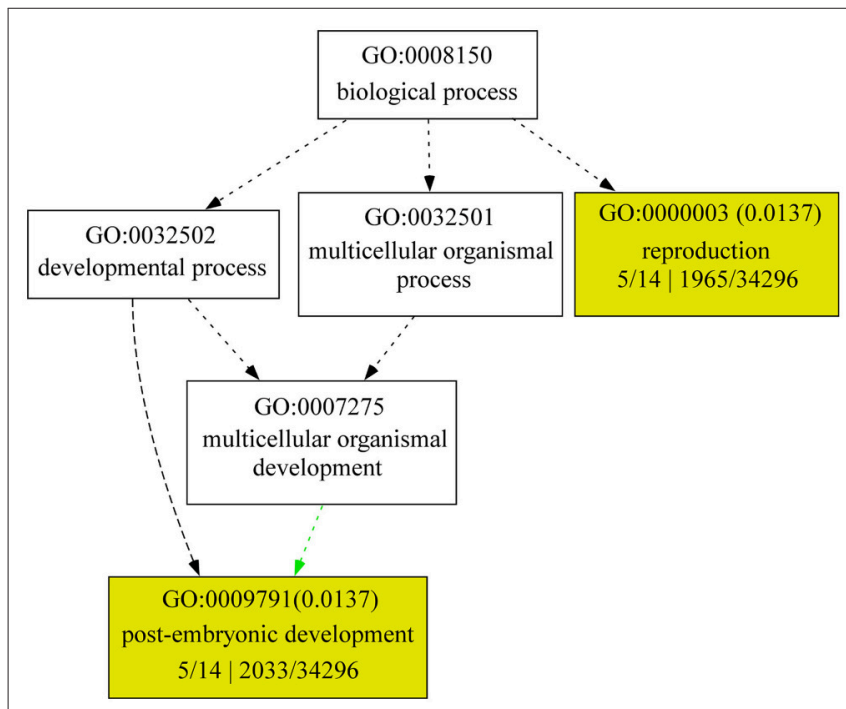

FIGURE 2 | GO enrichment analysis for changed proteins. GO terms, such as "biological process," "molecular function," and "cellular component," were identified using AGRIGO (http://bioinfo.cau.edu.cn/agriGO/index.php) with default significance levels (FDR < 0.05). 5/14 means gene number in input list; 1965/32496 and 2033/32496 means gene number in BG/Ref.

\section{Data Analysis}

The experimental data were analyzed using the SPSS 19.0 software, and the differences between treatments were compared with Student's $t$-test at 5 and $1 \%$ levels of probability (Lai et al., 2016).

\section{RESULTS}

\section{Germination Phenotype}

Seeds depicted a triphasic pattern of water uptake during germination under salt stress (Figure 1A). The uptake of water increased rapidly before $24 \mathrm{~h}$ imbibition (Phase I), followed by a plateau of seed imbibition from 24 to $96 \mathrm{~h}$ imbibition (Phase II). During Phase II, the seeds radicles began to emerge after $36 \mathrm{~h}$ imbibition, and the maximum germination (99.3\%) was attained after $96 \mathrm{~h}$ imbibition (Figure 1B). The imbibed seeds in the early Phase II ( $24 \mathrm{~h}$ ) of imbibition were collected for further proteomic analysis.

\section{Seed Imbibition Responses Proteins}

A total of 60 proteins were identified with significant differences at a change $\geq 1.5$-fold and $P<0.05$ between dry and imbibed 
$(24 \mathrm{~h})$ seeds (Supplementary Figure 1). Among them, 18 protein with significant differences at a change $\geq 2.0$-fold and $P<0.01$ were chosen for further analysis, and 14 proteins were successfully identified (Table 1; Supplementary Figure 2; Supplementary Table 2). Most of proteins were decreased after $24 \mathrm{~h}$ imbibition, while only three proteins, spots 840, 1135 and 1462 (cupin domain containing protein), 1224 (60S acidic ribosomal protein), and 1981 (glutelin), were increased. Additionally, the same protein was identified in different spots, including glucose-1-phosphate adenylyltransferase large subunit (spots 488, 633, 706, and 669), cupin domain containing protein (spots 840, 1135, and 1462), granule-bound starch synthase I (spots 870, 981, and 1092), and glutelin (spots 1426, 1536, 1652, and 1981).

\section{Meta-Analysis of Gene Expression}

Based on the publicly available microarray database, the genes encoding the identified proteins were summarized for an overview of the genes characteristics. Gene ontology (GO) analyses showed that five genes GLU2.1, GLU2.2, GLU2.3, GLU3, and GAS8 involved in the processes of reproduction (GO:0000003) and post-embryonic development (GO:0009791) (Figure 2). The higher transcript abundances of five genes $B P M, P K P, P P D, G A S 8$, and $A R S$ were observed at all of the developmental stages and in various tissues (Figure 3). However, the medium transcript abundances of another eight genes GAS1, GLU2.1, GLU2.2, GLU2.3, GLU3, CDP3.1, CDP3.2, and GSS were observed from the germination to the early reproductive (flowering) stages, with sharp up-regulation during seed development (milk and dough) stages.

\section{Dynamic Gene Expression during Seed Imbibition}

To elucidate the characterization of genes encoding the identified proteins during seed imbibition, dynamic qRT-PCR analyses were conducted in Jiucaiqing after 12, 24, and $48 \mathrm{~h}$ imbibition in distilled water and $150 \mathrm{mM} \mathrm{NaCl}$. The expression of eight genes such as BPM, PKP, GLU3, GLU2.1, GLU2.3, GAS8, GLU2.2, and GSS was increased during imbibition under both water and salt conditions in generally, while the expression of four genes such as $P P D, G A S 1, A R S$, and $A R P$ was stable (Figure 4). By comparison, the expression of nine genes, including $P K P$, GAS1, GAS8, GLU2.2, GLU3, PPD, ARP, CDP3.1, and CDP3.2, was significantly higher after 12 and $24 \mathrm{~h}$ imbibition under salt condition compared with water condition, suggesting the most genes encoding the identified proteins were earlier induced during imbibition by salt stress.

\section{Integrating Proteomics Data and QTLs for Seed Germination}

The genome regions of QTLs for seed germination in Jiucaiqing (Wang et al., 2011, 2014; Cheng et al., 2013; Liu et al., 2014) and genes encoding the identified proteins here were compared (Figure 5). Four genes, BPM, GLU2.3, GLU2.2, and CDP3.2, were near the regions of three QTLs for seed dormancy in Jiucaiqing. Two genes, CDP3.2 and GAS8, were mapped near the regions of QTLs for seed reserve utilization. The CDP3.1 gene was colocated in the region of $q I R-3$ for imbibition rate in distilled water and $q G P-3$ for germination percentage under salt condition.

\section{Role of a Cupin Domain Containing Protein}

As described above, CDP3.1 was near to the region of $q I R-$ 3 and $q G P-3$, suggesting that CDP3.1 plays important roles in seed germination. Therefore, one T-DNA insertion mutant was used to confirm the role of CDP3.1 on seed germination in rice. The insertion of T-DNA in the promoter of CDP3.1 gene was verified by PCR analysis (Figure 6A), and homozygous mutant line defective in CDP3.1 was confirmed at the DNA and mRNA levels (Figures 6B,C). Homozygous $c d p 3.1$ mutant had an decrease in seed germination as compared to WT under salt stress

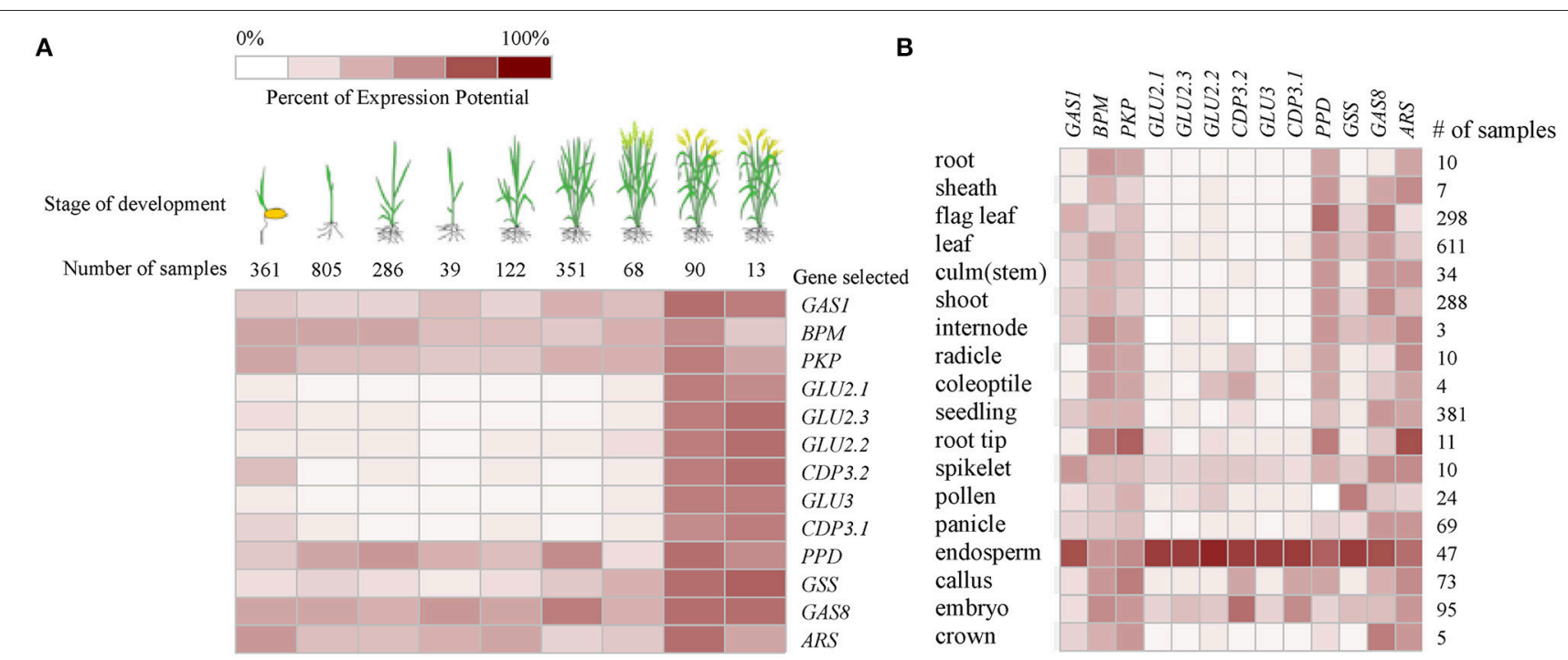

FIGURE 3 | Expression pattern of genes encoding the identified proteins in various developmental stages (A) and tissues (B) of rice based on the publicly available microarray data (http://www.genevestigator.com). 

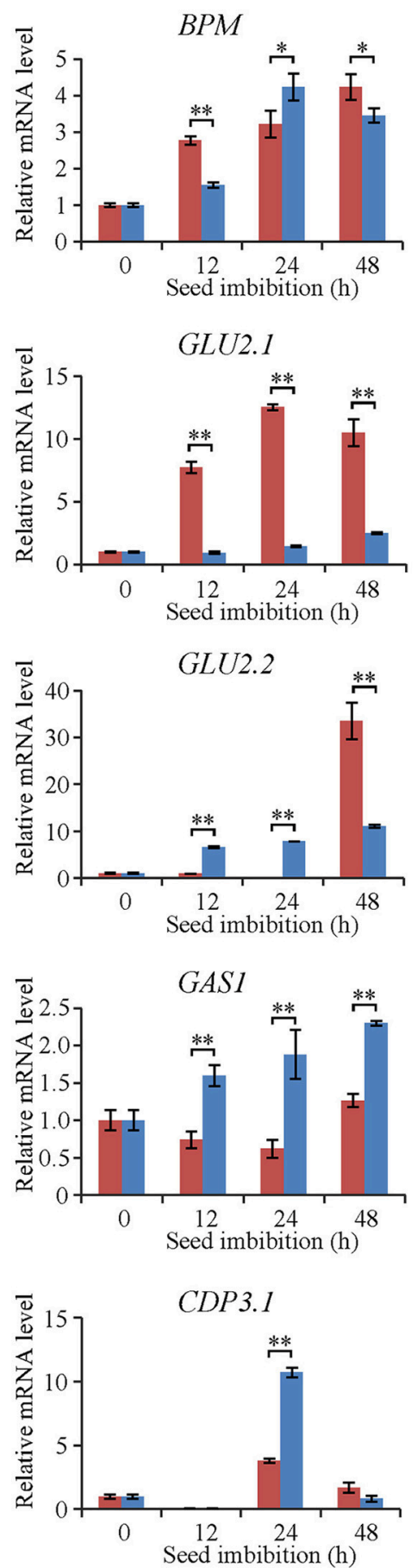
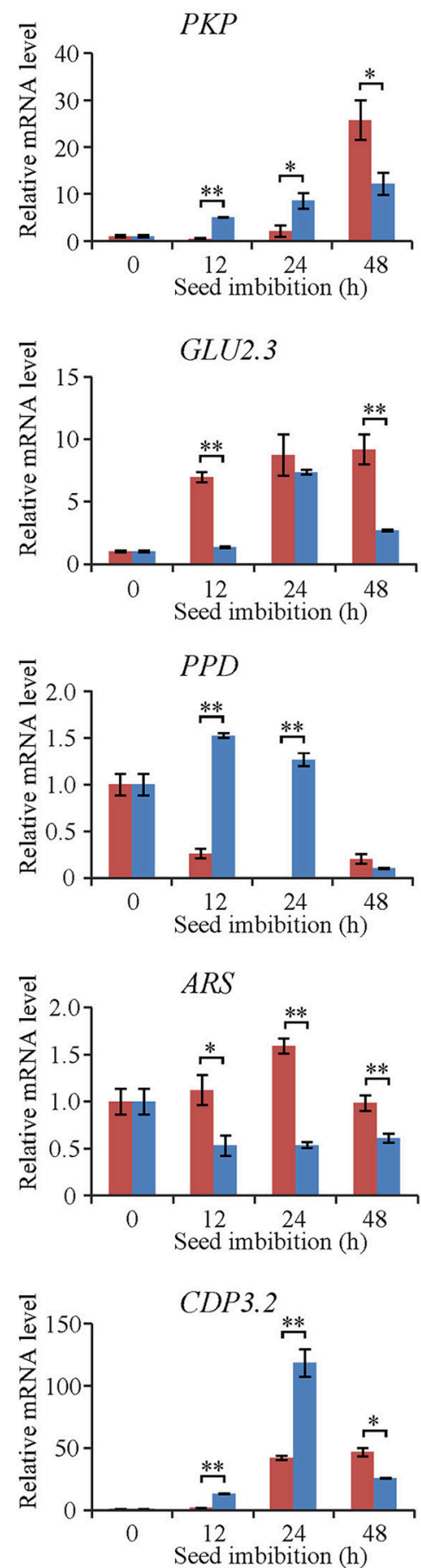
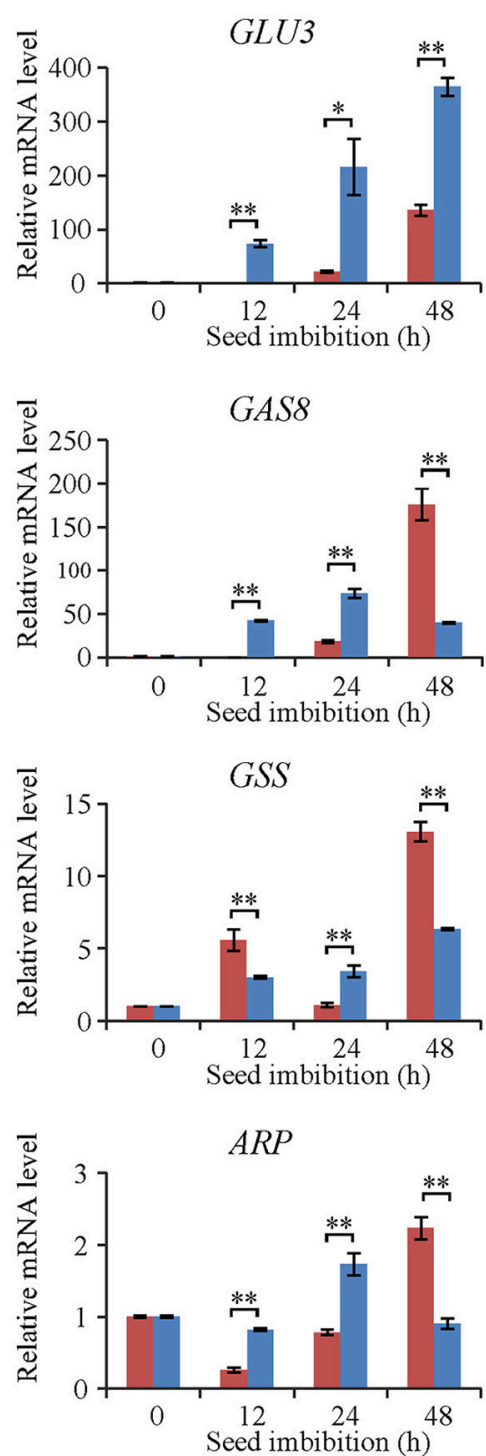

$-\mathrm{H}_{2} \mathrm{O}$

$150 \mathrm{mM} \mathrm{NaCl}$

FIGURE 4 | Expression pattern of genes during seed imbibition under distilled water and salt conditions based on quantitative RT-PCR analysis. The mRNA level of genes was normalized to that of $18 \mathrm{~S}$ ribosomal RNA gene control. Each column represents means \pm standard deviation. * and ${ }^{* *}$ indicated the significant difference at 5 and $1 \%$ levels between water and salt conditions, respectively.

(Figure 6D). There were no significant differences in GI after 10 days germination between WT and $c d p 3.1$ under water condition. Similarly, no significant differences were observed in GP and SP after 3, 5 and 7 days germination. However, those traits were significantly decreased in $c d p 3.1$ compared to WT under salt stress (Figures 6E-G). The dry and fresh weight of seedlings were significantly decreased in $c d p 3.1$ as compared to WT under salt stress (Figures 7A,B), while the level of $\mathrm{Na}^{+}$was not significantly accumulated in developing seeds, roots, and shoots of $c d p 3.1$ (Figure 7C). 


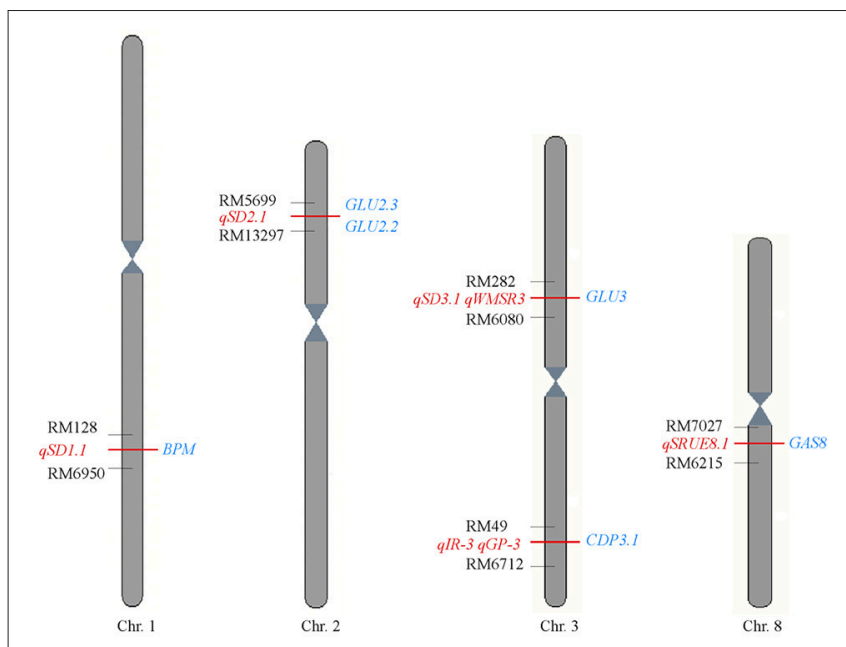

FIGURE 5 | Comparison of position between the identified proteins here with the previous QTLs for seed germination among

Jiucaiqing/IR26 RILs population. The proteins identified in this study are shown on the left (red), and the previously mapped QTLs are shown on the right (blue) (Wang et al., 2011, 2014; Cheng et al., 2013; Liu et al., 2014).

\section{DISCUSSION}

The influx of water into the cells of dry seeds during Phase I of imbibition is a physical process. Therefore, similar results were observed at the first $\sim 24 \mathrm{~h}$ in both distilled water (Cheng et al., 2017) and salt conditions in Jiucaiqing. Our previous study indicated that Phase II began at $\sim 24$ to $84 \mathrm{~h}$ in distilled water (Cheng et al., 2017). However, our current study indicated that the Phase II imbibition was prolonged to $96 \mathrm{~h}$ under salt stress. These results may explain, at least in part, why seeds had slower germination speed in salt solution than in distilled water due to a prolonged Phase II. Indeed, the maximum germination was attained after $60 \mathrm{~h}$ imbibition in distilled water (Cheng et al., 2017), but after $96 \mathrm{~h}$ imbibition under salt condition. In this study, we are mainly to identify genes involved in seed imbibition under salt stress. Therefore, the dry seeds of Jiucaiqing were used as control to perform the comparative proteomic assays in this study.

In the current study, the differences for expressed proteins at a change $>2.0$-fold and $P<0.01$ were used as screening criteria (Cheng et al., 2017). We identified 14 proteins involved in the early seed imbibition ( $24 \mathrm{~h}$ ) under salt stress. By comparison, the glucose-1-phosphate adenylyltransferase large subunit protein (GAS1 and GAS8) were identified under salt stress as well as in distilled water (Cheng et al., 2017), suggesting that GAS proteins are required for seed germination under various conditions. However, other proteins detected under salt stress may have specific functions. Furthermore, six proteins had been detected involved in seed germination in previous reports, including 2,3-bisphosphoglycerate-independent phosphoglycerate mutase (Graña et al., 1993), cupin domain containing protein (Lapik and Kaufman, 2003), glutelin (Yang et al., 2007), 60S ribosomal protein (Rajjou et al., 2008), pyruvate phosphoglycerate dikinase (Weitbrecht et al., 2011), and granule-bound starch synthase I
(Liu et al., 2015). However, the argininosuccinate synthase and pyruvate phosphate dikinase protein were first time found to be involved in seed germination under salt stress. Six genes encoding the proteins identified here are near the regions of QTLs for seed dormancy, seed reserve utilization, seed imbibition and seed germination in our previous studies (Wang et al., 2011, 2014; Cheng et al., 2013; Liu et al., 2014). It indicates that these genes might be important for seed germination.

To further evaluate the function of the genes, we categorized them based on their known functions using GO classifications. We found that glucose-1-phosphate adenylyltransferase large subunit protein and glutelin are significantly associated with the processes of reproduction and post-embryonic development. Glucose-1-phosphate adenylyltransferase is an enzyme that catalyzes the formation of adenosine triphosphate (ATP) to adenosine diphosphate (ADP) and vice versa. In previous study, seed dormancy QTL $q S d n-1$ was associated with glucose1-phosphate adenylyltransferase large subunit 1 (Qin et al., 2010). The cereals store reserve proteins (globulin and glutelins) provide nitrogen for seed germination and early seedling growth (Kishimoto et al., 2001; Yano et al., 2001). The storage reserve proteins glutelin (GLU2.1, GLU2.2, and GLU3) are accumulated during seed development and were found to be down-regulated during seed imbibition in this study. Similarly, Yang et al. (2007) indicated that the glutelin was down-regulated at the late stage of germination Phase II ( $48 \mathrm{~h}$ ). However, we also found that the glutelin GLU2.3 was up-regulated during seed imbibition under salt stress. The function of glutelin GLU2.3 during seed germination need to be further researched.

The changes of proteins related to energy metabolism, e.g., pyruvate phosphate dikinase, 2,3-bisphosphoglycerateindependent phosphoglycerate mutase and phosphoglycerate kinase protein, were identified in the early Phase II (24h) of imbibition under salt stress in rice. Pyruvate phosphate dikinase is one of the main limiting enzymes in the process of glycolysis that catalyzes the inter-conversion of ATP and pyruvate with adenine monophosphate (AMP) and phosphoenolpyruvate (PEP; Evans and Wood, 1968). 2,3-biphosphoglycerateindependent phosphoglycerate mutase is a key enzymatic activity in glycolysis and catalyses the reversible interconversion of 3-phosphoglycerate to 2-phosphoglycerate (Zhao and Assmann, 2011). Phosphoglycerate kinase is an enzyme that catalyzes the reversible transfer of a phosphate group from 1,3-bisphosphoglycerate (1,3-BPG) to ADP producing 3phosphoglycerate (3-PG) and ATP (Fermo et al., 2012). These results suggest that those enzymes play important roles in energy metabolism during early seed imbibition under salt stress in rice. An increased ATP requirement might be required for $\mathrm{Na}^{+}$ extrusion and maintaining the membrane potential. The link between the energy metabolism and avoidance mechanisms of salt stress would be further investigated.

In order to clarify the characterization of these gene expression during seed imbibition, a quantitative PCR-based gene expression experiment was conducted. By comparison, the most of identified proteins were down-regulated after 24 $\mathrm{h}$ imbibition, while the mRNA levels were up-regulated. Only five proteins (ARS, ARP, CDP3.1, CDP3.2, and GLU2.3) behaved 
A

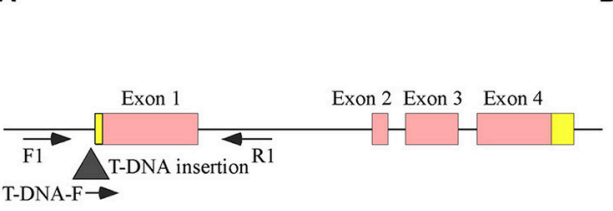

D

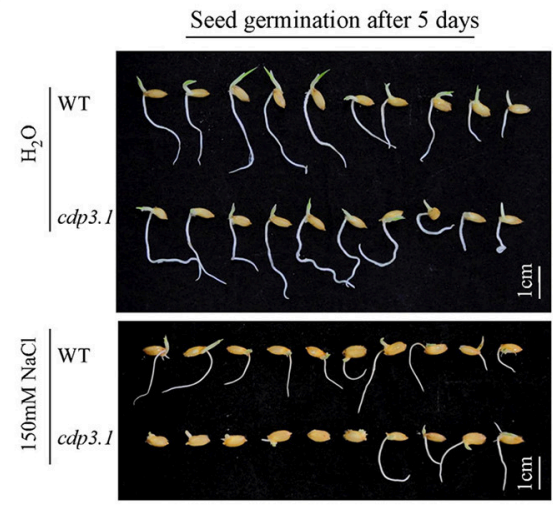

$\mathbf{F}$

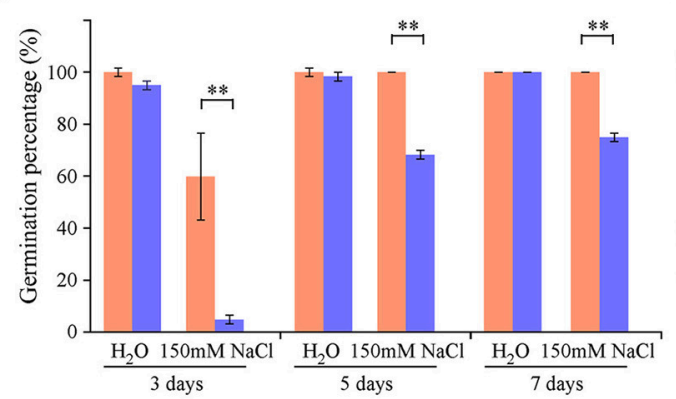

$\mathrm{E}$

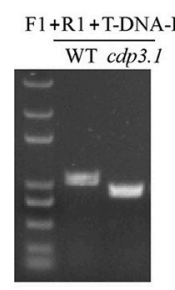

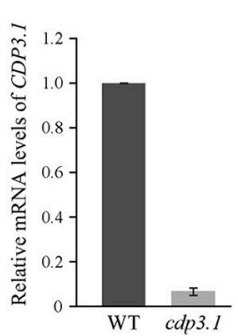

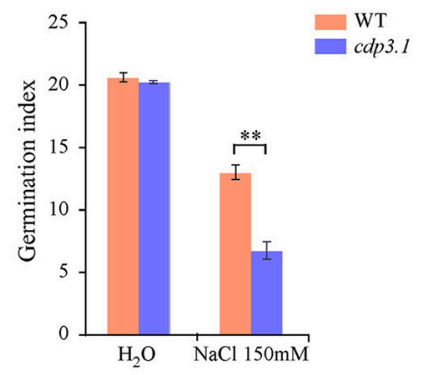

G

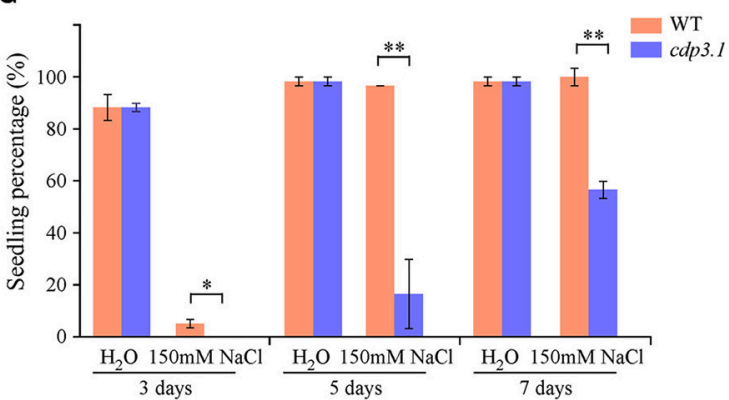

FIGURE 6 | Comparison of seed germination between wide type (WT) and CDP3.1 mutant line (cdp3.1) under water and salt stress conditions. (A) Gene structure of CDP3.1 with a T-DNA insertion and the locations of the primers used for PCR analysis. Black triangle represents the T-DNA. Red and yellow boxes represent exons and UTR of CDP3.1, respectively. Solid lines represent introns. F, R, and T-DNA-F primers used for genotyping PCR. (B) PCR of genomic DNA from WT and cdp3.1. (C) Quantitative RT-PCR analysis of CDP3.1 mRNA level from WT and cdp3.1 seeds. The mRNA level of CDP3.1 was normalized to that of $18 \mathrm{~S}$ ribosomal RNA gene control. (D) Seed germination of WT and cdp3.1 after 5 days under water and $150 \mathrm{mM} \mathrm{NaCl}$ conditions. (E) Germination index of WT and cdp3.1 after 10 days under water and $150 \mathrm{mM} \mathrm{NaCl}$ conditions. (F) Germination percentage of WT and cdp3.1 after 3, 5, and 7 days under water and $150 \mathrm{mM} \mathrm{NaCl}$ conditions. (G) Seedling percentage of WT and cdp3.1 after 3, 5, and 7 days under water and $150 \mathrm{mM} \mathrm{NaCl}$ conditions. Each column represents means \pm standard deviation. ${ }^{*}$ and ${ }^{* *}$ indicated the significant difference at 5 and $1 \%$ levels, respectively.

the similar transcript and protein expression patterns during seed germination. The reason might be that the catabolism of these storage proteins at the early imbibition stage is necessary for seed germination, while the increase of mRNA level at the end of germination for de novo protein synthesis is essential for vigorous seedling growth. Interestingly, the expression of the majority genes encoding the identified proteins was significantly higher under salt condition compared with water condition in the early imbibition stage (12 and $24 \mathrm{~h}$ ). It suggests that the earlier induction of these genes might be important for successful seed germination under salt condition. More experiments should be performed to confirm this hypothesis.
It has been estimated previously that cupins had at least 18 different functional subclasses (Dunwell et al., 2001), which include enzymatic functions like hydrolases, dioxygenases, decarboxylases, isomerases, and epimerases non-enzymatic functions such as seed storage, binding to auxin, and nuclear transcription factors (Dunwell et al., 2001, 2004). In this study, we found that the induction of cupin domain containing protein CDP3.1 (globulin) benefits seed germination and seedling growth under salt stress. However, the improvement of salinity tolerance by CDP3.1 is not by reducing $\mathrm{Na}^{+}$uptake of seedlings, indicating it may play roles on salinity tolerance by other mechanism. For example, the accumulation of storage proteins are associated 

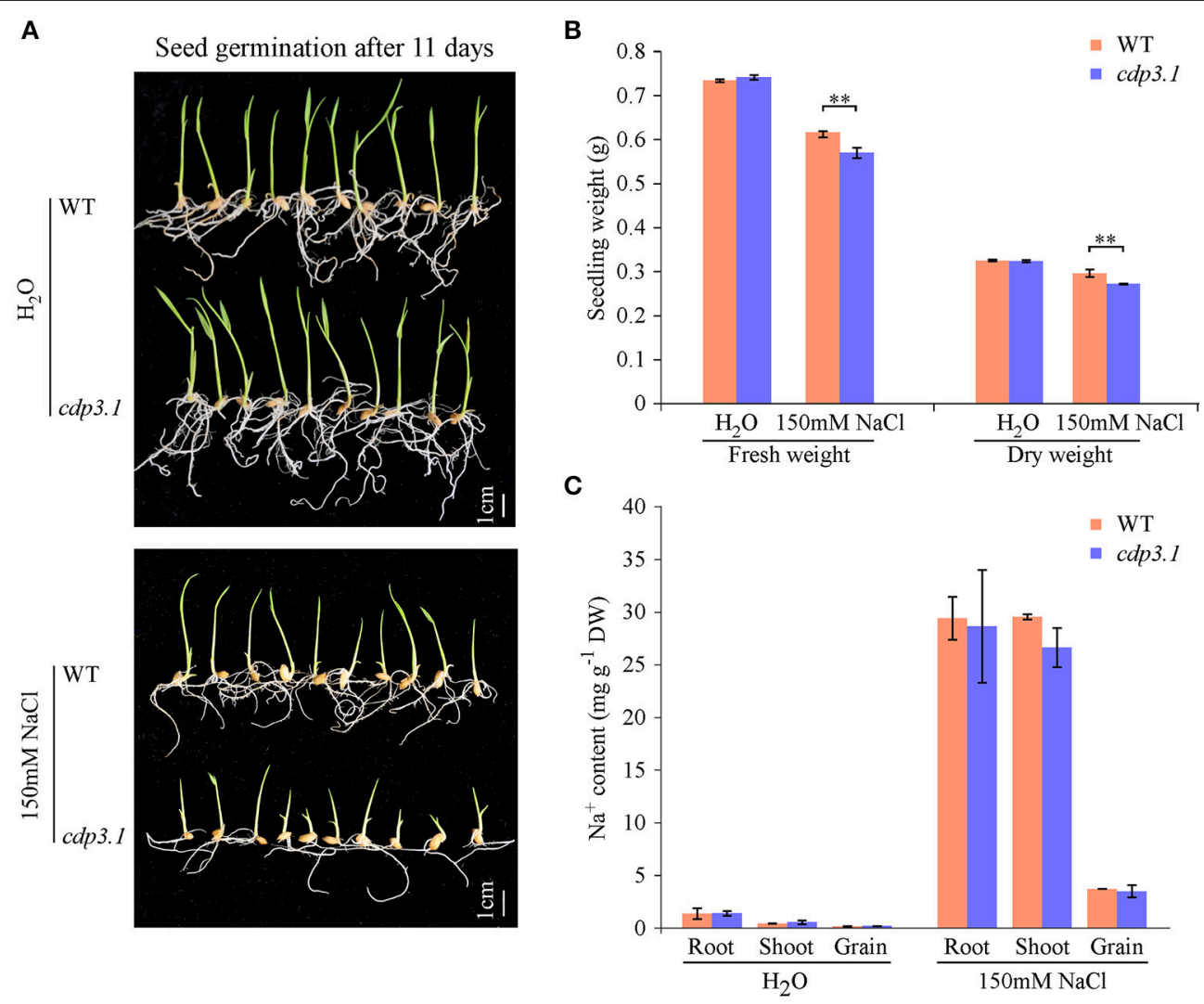

FIGURE 7 | Comparison of seedling growth and $\mathrm{Na}^{+}$ion accumulation in tissues between wide type (WT) and CDP3.1 mutant line (cdp3.1) under water and salt stress conditions. (A) Seedling growth of WT and cdp3.1 after 11 days under water and $150 \mathrm{mM} \mathrm{NaCl}$ conditions. (B) Fresh and dry seedling weight of WT and cdp3.1 after 11 days under water and $150 \mathrm{mM} \mathrm{NaCl}$ conditions. (C) Accumulation of $\mathrm{Na}^{+}$in grains, roots, and shoots of WT and cdp3.1 after 11 days under water and $150 \mathrm{mM} \mathrm{NaCl}$ conditions. Each column represents means \pm standard deviation. ${ }^{* \star}$ indicated the significant difference at $1 \%$ level.

with desiccation tolerance (Bäumlein et al., 1995), and they also be used as a source of energy for the germinating embryo (Dunwell et al., 2000). In this study, the accumulation of CDP3.1 might improve seed quality during seed development, and then provide more energy for seed germination under salt stress. The function of CDP3.1 on seed germination should be confirmed using more transgenic lines or mutant lines; the construction of RNAi transgenic lines and CRISPR/Cas9 mutant lines for CDP3.1 is being investigated in rice.

In summary, imbibition is a critical process during seed germination. To detect proteins which contribute to seed germination under salt stress, the changes of proteomic in $24 \mathrm{~h}$ imbibed seeds under salt stress were investigated in this study. We identified 14 proteins involved in seed imbibition under salt stress in rice. The most of proteins were down-regulated by imbibition; it appears that the early imbibition process is mediated by protein catabolism rather than by de novo protein synthesis. The majority of these proteins were involved in energy supply and storage protein. In particular, our results confirmed the role of cupin globulin protein CDP3.1 in governing seed germination under salt stress. The function of these identified proteins in seed germination need to be studied in the future.

\section{AUTHOR CONTRIBUTIONS}

Conceived and designed the experiments: ZW and HZ. Performed the experiments: EX, MC, and CZ. Analyzed the data: $\mathrm{HH}$ and YC. Wrote the paper: ZW.

\section{ACKNOWLEDGMENTS}

This work was supported by the Natural Science Foundation of Jiangsu Province (Grant Nos. BK20150675; BK20161451), the Science and Technology Project of Jiangsu Province (No. BE2016380), the Fundamental Research Funds for the Central Universities (Grant Nos. KYZ201402; KYZ201505), and the National Science and Technology Support Program (2015BAD01B01-2).

\section{SUPPLEMENTARY MATERIAL}

The Supplementary Material for this article can be found online at: http://journal.frontiersin.org/article/10.3389/fpls.2016. 02006/full\#supplementary-material

Supplementary Table 1 | The primer pairs of genes for quantitative RT-PCR. 
Supplementary Table 2 | Peptide sequences identified by MS-MS sequencing and corresponding to proteins identified in rice of this work.

Supplementary Figure 1 | 2-D analysis of rice proteome during seed germination under $150 \mathrm{mM} \mathrm{NaCl}$ condition. 2-D gel profiles of total proteins from dry seeds (A) and $24 \mathrm{~h}$ imbibed seeds (B), and the proteins statistically significant differences $(P<0.05)$ at least 1.5 -fold between dry and $24 \mathrm{~h}$ imbibed

\section{REFERENCES}

Bäumlein, H., Braun, H., Kakhovskaya, I. A., and Shutov, A. D. (1995). Seed storage proteins of spermatophytes share a common ancestor with desiccation proteins of fungi. J. Mol. Evol. 41, 1070-1075. doi: 10.1007/BF00173188

Cheng, J., Wang, L., Zeng, P., He, Y., Zhou, R., Zhang, H., et al. (2017). Identification of genes involved in rice seed priming in the early imbibition stage. Plant Biol. 19, 61-69. doi: 10.1111/plb.12438

Cheng, X., Cheng, J., Huang, X., Lai, Y., Wang, L., Du, W., et al. (2013). Dynamic quantitative trait loci analysis of seed reserve utilization during three germination stages in rice. PLOS ONE 8:e80002. doi: 10.1371/journal.pone.0080002

Du, W., Cheng, J., Cheng, Y., Wang, L., He, Y., Wang, Z., et al. (2015). Physiological characteristics and related gene expression of after-ripening on seed dormancy release in rice. Plant Biol. 17, 1156-1164. doi: 10.1111/plb.12371

Du, Z., Zhou, X., Ling, Y., Zhang, Z., and Su, Z. (2010). agriGO: a GO analysis toolkit for the agricultural community. Nucleic Acids Res. 38, W64-W70. doi: 10.1093/nar/gkq310

Dunwell, J. M., Culham, A., Carter, C. E., Sosa-Aguirre, C. R., and Goodenough, P. W. (2001). Evolution of functional diversity in the cupin superfamily. Trends Biochem. Sci. 26, 740-746. doi: 10.1016/S0968-0004(01)01981-8

Dunwell, J. M., Khuri, S., and Gane, P. J. (2000). Microbial relatives of the seed storage proteins of higher plants: Conservation of structure and diversification of function during evolution of the cupin superfamily. Microbiol. Mol. Biol. Rev. 64, 153-179. doi: 10.1128/MMBR.64.1.153-179.2000

Dunwell, J. M., Purvis, A., and Khuri, S. (2004). Cupins: the most functionally diverse protein superfamily? Phytochemistry 65, 7-17. doi: 10.1016/j.phytochem.2003.08.016

Evans, H. J., and Wood, H. G. (1968). The mechanism of the pyruvate, phosphate dikinase reaction. Proc. Natl. Acad. Sci. U.S.A. 61, 1448-1453. doi: 10.1073/pnas.61.4.1448

Fermo, E., Bianchi, P., Chiarelli, L. R., Maggi, M., Mandara, G. M., Vercellati, C., et al. (2012). A new variant of phosphoglycerate kinase deficiency (p.I371K) with multiple tissue involvement: molecular and functional characterization. Mol. Genet. Metab. 106, 455-461. doi: 10.1016/j.ymgme.2012.05.015

Fu, Z., Jin, X., Ding, D., Li, Y., Fu, Z., and Tang, J. (2011). Proteomic analysis of heterosis during maize seed germination. Proteomics 11, 1462-1472. doi: 10.1002/pmic.201000481

Fujino, K., Sekiguchi, H., Sato, T., Kiuchi, H., Nonoue, Y., Takeuchi, Y., et al. (2004). Mapping of quantitative trait loci controlling low-temperature germinability in rice (Oryza sativa L.). Theor. Appl. Genet. 108, 794-799. doi: 10.1007/s00122-003-1509-4

Graña, X., Broceño, C., Garriga, J., de la Ossa, P. P., and Climent, F. (1993). Phosphoglycerate mutase activity and mRNA levels during germination of maize embryos. Plant Sci. 89, 147-151. doi: 10.1016/0168-9452(93)90122-G

Guo, M., Rupe, M. A., Zinselmeier, C., Habben, J., Bowen, B. A., and Smith, O. S. (2004). Allelic variation of gene expression in maize hybrids. Plant Cell 16, 1707-1716. doi: 10.1105/tpc.022087

Han, C., He, D., Li, M., and Yang, P. (2014a). In-depth proteomic analysis of rice embryo reveals its important roles in seed germination. Plant Cell Physiol. 55, 1826-1847. doi: 10.1093/pcp/pcu114

Han, C., Yang, P., Sakata, K., and Komatsu, S. (2014b). Quantitative proteomics reveals the role of protein phosphorylation in rice embryos during early stages of germination. J. Proteome Res. 13, 1766-1782. doi: 10.1021/pr401295c

He, D., Han, C., Yao, J., Shen, S., and Yang, P. (2011). Constructing the metabolic and regulatory pathways in germinating rice seeds through proteomic approach. Proteomics 11, 2693-2713. doi: 10.1002/pmic.201000598 seeds (C). An equal amount (100 $\mu \mathrm{g})$ of total protein extracts was loaded in each gel.

Supplementary Figure 2 | Magnified views of the gels showing down- and up-regulated proteins statistically significant differences $(P<0.01)$ at least 2-fold between $24 \mathrm{~h}$ imbibed and dry seeds under $150 \mathrm{mM} \mathrm{NaCl}$ condition. Proteins eluted from these spots were successfully identified by MALDI-TOF-MS (see Table 1)

$\mathrm{He}, \mathrm{H}$., and Li, J. (2008). Proteomic analysis of phosphoproteins regulated by abscisic acid in rice leaves. Biochem. Biophys. Res. Commun. 371, 883-888. doi: 10.1016/j.bbrc.2008.05.001

Jeon, J. S., Lee, S., Jung, K. H., Jun, S. H., Jeong, D. H., Lee, J., et al. (2000). T-DNA insertional mutagenesis for functional genomics in rice. Plant J. 22, 561-570. doi: 10.1046/j.1365-313x.2000.00767.x

Jeong, D. H., An, S., Kang, H. G., Moon, S., Han, J. J., Park, S., et al. (2002). TDNA insertional mutagenesis for activation tagging in rice. Plant Physiol. 130, 1636-1644. doi: 10.1104/pp.014357

Kishimoto, T., Hori, H., Takano, D., Nakano, Y., Watanabe, M., and Mitsui, T. (2001). Rice alpha-mannosidase digesting the high mannose glycopeptide of glutelin. Physiol. Plant. 112, 15-24. doi: 10.1034/j.1399-3054.2001.1120103.x

Lai, Y., Cheng, J., He, Y., Yang, B., Wang, Z., and Zhang, H. (2016). Identification of QTLs with additive, epistatic, and QTL $\times$ seed maturity interaction effects for seed vigor in rice. Plant Mol. Biol. Rep. 34, 160-171. doi: 10.1007/s11105-015-0913-7

Lapik, Y. R., and Kaufman, L. S. (2003). The Arabidopsis cupin domain protein AtPirin1 interacts with the G protein alpha-subunit GPA1 and regulates seed germination and early seedling development. Plant Cell 15, 1578-1590. doi: 10.1105/tpc.011890

Lin, H. X., Zhu, M. Z., Yano, M., Gao, J. P., Liang, Z. W., Su, W. A., et al. (2004) QTLs for $\mathrm{Na}+$ and $\mathrm{K}+$ uptake of the shoots and roots controlling rice salt tolerance. Theor. Appl. Genet. 108, 253-260. doi: 10.1007/s00122-003-1421-y

Liu, L., Lai, Y., Cheng, J., Wang, L., Du, W., Wang, Z., et al. (2014). Dynamic quantitative trait locus analysis of seed vigor at three maturity stages in rice. PLoS ONE 9:e115732. doi: 10.1371/journal.pone.0115732

Liu, S. J., Xu, H. H., Wang, W. Q., Li, N., Wang, W. P., Moller, I. M., et al. (2015). A proteomic analysis of rice seed germination as affected by high temperature and ABA treatment. Physiol. Plant. 154, 142-161. doi: 10.1111/ppl.12292

Livak, K. J., and Schmittgen, T. D. (2001). Analysis of relative gene expression data using real-time quantitative PCR and the 2(-DDC(T)) method. Methods 25, 402-408. doi: 10.1006/meth.2001.1262

Maggio, A., Barbieri, G., Raimondi, G., and De Pascale, S. (2010). Contrasting effects of GA3 treatments on tomato plants exposed to increasing salinity. J. Plant Growth Regul. 29, 63-72. doi: 10.1007/s00344-009-9114-7

Møller, I. S., Gilliham, M., Jha, D., Mayo, G. M., Roy, S. J., Coates, J. C., et al. (2009). Shoot $\mathrm{Na}+$ exclusion and increased salinity tolerance engineered by cell typespecific alteration of $\mathrm{Na}+$ transport in Arabidopsis. Plant Cell. 21, 2163-2178. doi: $10.1105 /$ tpc. 108.064568

Qin, H. D., Wu, F. Q., Xie, K., Cheng, Z. J., Guo, X. P., Zhang, X., et al. (2010). Transcriptomics analysis identified candidate genes colocalized with seed dormancy QTLs in rice (Oryza sativa L.). J. Plant Biol. 53, 330-337. doi: 10.1007/s12374-010-9120-0

Rajjou, L., Lovigny, Y., Groot, S. P., Belghazi, M., Job, C., and Job, D. (2008) Proteome-wide characterization of seed aging in Arabidopsis: a comparison between artificial and natural aging protocols. Plant Physiol. 148, 620-641. doi: 10.1104/pp.108.123141

Sano, N., Permana, H., Kumada, R., Shinozaki, Y., Tanabata, T., Yamada, T., et al. (2012). Proteomic analysis of embryonic proteins synthesized from long-lived mRNAs during germination of rice seeds. Plant Cell Physiol. 53, 687-698. doi: $10.1093 / \mathrm{pcp} / \mathrm{pcs} 024$

Takehisa, H., Shimodate, T., Fukuta, Y., Ueda, T., Yano, M., Yamaya, T., et al. (2004). Identification of quantitative trait loci for plant growth of rice in paddy field flooded with salt water. Field Crops Res. 89, 85-95. doi: 10.1016/j.fcr.2004.01.026

Wang, L., Cheng, J., Lai, Y., Du, W., Huang, X., Wang, Z., et al. (2014). Identification of QTLs with additive, epistatic and QTL $\times$ development 
interaction effects for seed dormancy in rice. Planta 239, 411-420. doi: 10.1007/s00425-013-1991-0

Wang, Z., Cheng, J., Chen, Z., Huang, J., Bao, Y., Wang, J., et al. (2012b). Identification of QTLs with main, epistatic and QTL $\times$ environment interaction effects for salt tolerance in rice seedlings under different salinity conditions. Theor. Appl. Genet. 125, 807-815. doi: 10.1007/s00122-0121873-z

Wang, Z., Chen, Z., Cheng, J., Lai, Y., Wang, J., Bao, Y., et al. (2012a). QTL analysis of $\mathrm{Na}+$ and $\mathrm{K}+$ concentrations in roots and shoots under different levels of $\mathrm{NaCl}$ stress in rice (Oryza sativa L.). PLoS ONE 7:e51202. doi: 10.1371/journal.pone.0051202

Wang, Z. F., Wang, J. F., Bao, Y. M., Wang, F. H., and Zhang, H. S. (2010). Quantitative trait loci analysis for rice seed vigor during the germination stage. J. Zhejiang Univ. Sci. B 11, 958-964. doi: 10.1631/jzus.B1000238

Wang, Z., Wang, J., Bao, Y., Wu, Y., and Zhang, H. (2011). Quantitative trait loci controlling rice seed germination under salt stress. Euphytica 178, 297-307. doi: 10.1007/s10681-010-0287-8

Weitbrecht, K., Muller, K., and Leubner-Metzger, G. (2011). First off the mark: early seed germination. J. Exp. Bot. 62, 3289-3309. doi: 10.1093/jxb/ err030

Xu, H. H., Liu, S. J., Song, S. H., Wang, R. X., Wang, W. Q., and Song, S. Q. (2016). Proteomics analysis reveals distinct involvement of embryo and endosperm proteins during seed germination in dormant and non-dormant rice seeds. Plant Physiol. Biochem. 103, 219-242. doi: 10.1016/j.plaphy.2016. 03.007
Yang, P., Li, X., Wang, X., Chen, H., Chen, F., and Shen, S. (2007). Proteomic analysis of rice (Oryza sativa) seeds during germination. Proteomics 7, 3358-3368. doi: 10.1002/pmic.200700207

Yano, H., Wong, J. H., Cho, M. J., and Buchanan, B. B. (2001). Redox changes accompanying the degradation of seed storage proteins in germinating rice. Plant Cell Physiol. 42, 879-883. doi: 10.1093/pcp/pce119

Zhang, H., He, D., Yu, J. L., Li, M., Damaris, R. N., Gupta, R., et al. (2016). Analysis of dynamic protein carbonylation in rice embryo during germination through AP-SWATH. Proteomics 16, 989-1000. doi: 10.1002/pmic.201500248

Zhao, Z., and Assmann, S. M. (2011). The glycolytic enzyme, phosphoglycerate mutase, has critical roles in stomatal movement, vegetative growth, and pollen production in Arabidopsis thaliana. J. Exp. Bot. 62, 5179-5189. doi: $10.1093 /$ jxb/err223

Conflict of Interest Statement: The authors declare that the research was conducted in the absence of any commercial or financial relationships that could be construed as a potential conflict of interest.

Copyright (c) $2017 \mathrm{Xu}$, Chen, He, Zhan, Cheng, Zhang and Wang. This is an openaccess article distributed under the terms of the Creative Commons Attribution License (CC BY). The use, distribution or reproduction in other forums is permitted, provided the original author(s) or licensor are credited and that the original publication in this journal is cited, in accordance with accepted academic practice. No use, distribution or reproduction is permitted which does not comply with these terms. 